\title{
THE IMPORTANCE OF PROFESSIONAL COMPETENCIES IN THE HUMAN CAPITAL EFFECTIVE USAGE
}

Valentina Pavlovska

BA School of Business and Finance

\begin{abstract}
The research was done on how the effectiveness of human capital exploitation is influenced by the relevance of skills required by employer. The research problem: the mismatch of employee skills to employer's requirements gives cause to an inefficient use of human capital, causing damage to both employers and employees.

Study objective: To ascertain employees, working in the banking sector, skills, education and qualification compliance with industry requirements and determine how discrepancies affect employee motivation. The ability to make impartial self-appraisal of own activities and competences, is particularly important, because only a man who is able to impartially assess may plan the future, choose the right career directions, evaluate own characteristics, and identify cumbersome obstacles.
\end{abstract}

Keywords: Human capital, labour market, qualification compliance, skills mismatch, unemployment, the job training.

\section{Introduction}

At the beginning of the new millennium, Europe and the world undergone rapid changes influenced by the technology, science and globalization processes. Ever increasing development of information in the gross domestic product, and in the development of hi-economic sectors, advance new requirements in human resource development.

The labour market requirements for the employees are changing rapidly. Therefore there are increasing issues within the skilled employee sector as well as the concern that human capital is being inefficiently used. Both are important at a national level for employers and employees.

Aim of the study: to ascertain employees, working in the banking sector, skills, education and qualification compliance with industry requirements and determine how discrepancies affect employee motivation.

The research was done using the methodology applied in Portugal in bank employee testing, based on employees' self-esteem.

\section{The Development of the Concept "Human Capital"}

The traditional economic theory states that the resources necessary for the production process are - "nature, labour and capital" and the entrepreneurial abilities on which depend the management of these resources. However, in the early 1960s the USA economists begun to develop the theory of human's fundamental importance in the use of production resources. "A human being is the only element capable of creating new values, other variables - money and its "relative" credit, raw materials, equipment and energy are in an inert state and function on a human being's wish" (Schultz, 1961). The diversity and often 
unpredictability of human behaviour makes difficult the evaluation process of this resource. Schultz admits that in the early 60 s it was not easy to refer the concept "capital" to the human beings, though he associated this theory with the investments in human beings. He compared the acquisition process of knowledge and skills to the costs for the purchase of production means. By investing in people, the employers can also control this aspect of means of production and to ensure the increase of production". Gary S. Becker in his turn notes that every human's activity outside the marker has a rational justification. The investment of means in education, health protection and other activities is based on rational justifications - in order to obtain higher returns in future. The expenses related to these activities are regarded as investments in human capital. A human capital is understood as an aggregate of knowledge, skills, abilities, motivation and energy possessed by a human and which can be used in a certain period of time with a goal to create the new material values or to provide services (Becker, 1975). It is regarded as a capital because it has an impact on human's future income and quality of life. The human's working capacity and its utilization skills is a special form of capital and its development requires substantial time and material resources investments. Thus, any activities capable of generating human's further flow of income may be regarded as human capital.

The concept developed by these authors is called "Chicago School" in the circles of theorists of economics (Becker, 1975).

Further both these, and many other authors, which have developed the theory of human capital, substantiated its importance in the development of corporations, regions and state.

"Chicago School" theory defines the expected return from investments in human capital. They are;

- a higher income level throughout life;

- a higher degree of satisfaction working in a chosen profession throughout life;

- a higher standard of life;

- an ability to evaluate and to participate in various activities outside the market.

The issues of development and use of human capital were raised when the Lisbon Strategy (European Commission, 2007) was adopted, which aimed to solve the problems associated with slow development of European Union, technological backwardness, insufficient growth of labour productivity. In accordance with its main aim the European Union was to become in 2010 the most competitive and dynamic knowledge-based economics in the world.

The researchers admit that an adverse demographic development and insufficient utilization of human capital, as well as a constant brain drain and inadequate investments in education, began to threaten the prospects of the regions. The problems mentioned may cause "domino" effect on Western Europe and Europe's place in the world economics unless urgent measures are 
taken. There is a risk that in the next decades the Central and Eastern countries could become the sparsely populated territories with insufficient manpower. There is a question about the long-term support of these countries, which have given so much to the European history, economics and changes.

Taking into consideration the attitude of European Union towards development of human capital, several researches were carried out in Latvia. In the Human Development Report of 2006/2007 "My Gold is my People" it is marked that human capital is person's abilities and skills set on which depends their potential of economic and social activities (Pārskats par tautas attīstību, 2007).

In 2006 in Bank of Latvia a research "The Role of Production Progress and Human Capital in the Economic Growth of Latvia" was carried out aiming to estimate the importance of human capital in the growth of national economy, modelling the production function where one of its components would be human capital value.

In strategy "Latvia's Sustainable Development Strategy until 2030" developed in 2010 it is defined that "Human capital of the state is an average amount of the knowledge, talents and skills of inhabitants multiplied by the number of economically active people. Value of human capital is characterized by the base, use and productivity of its knowledge, skills and talents. The investments in human capital are education, health care, professional training and other activities making people economically more productive and emotionally richer." Human capital itself cannot create the values, cannot ensure the social and economic development, i.e. people do not operate in isolation from society. Social networks and institutions determine the individual's economic value their motivation and opportunities to develop and use this capital in order to create goods and services, which can be sold.

Thus, human capital is contextual and to measure accurately its value is difficult. In order it would be possible to measure human capital, it is necessary to find out which skills and abilities are required in a corresponding social context.

\section{The Role of Matching Professional Competences in the Use of Human Capital}

In the context of limited resources and adverse demographic trends, rationally evaluated investments and productive use of human capital is the main way how to overcome a fall of economic growth and financial stress in long-term.

Currently one of three able-bodied Europeans has a low qualification or does not have it at all, therefore their chances of being hired are $40 \%$ lower than for people with medium level qualifications. On average European Union citizens with a high skills level are employed in $84 \%$ cases, with medium skills level $70 \%$ and with low skills level $-49 \%$. The corporations training their employees are 2, 5 times less likely to go out their business than those corporations, which do not train their employers (European Commission, 2010). 
Improving the skills of population is a benefit for all - economy, society, employers and, of course, for the individual itself (See Picture 1).

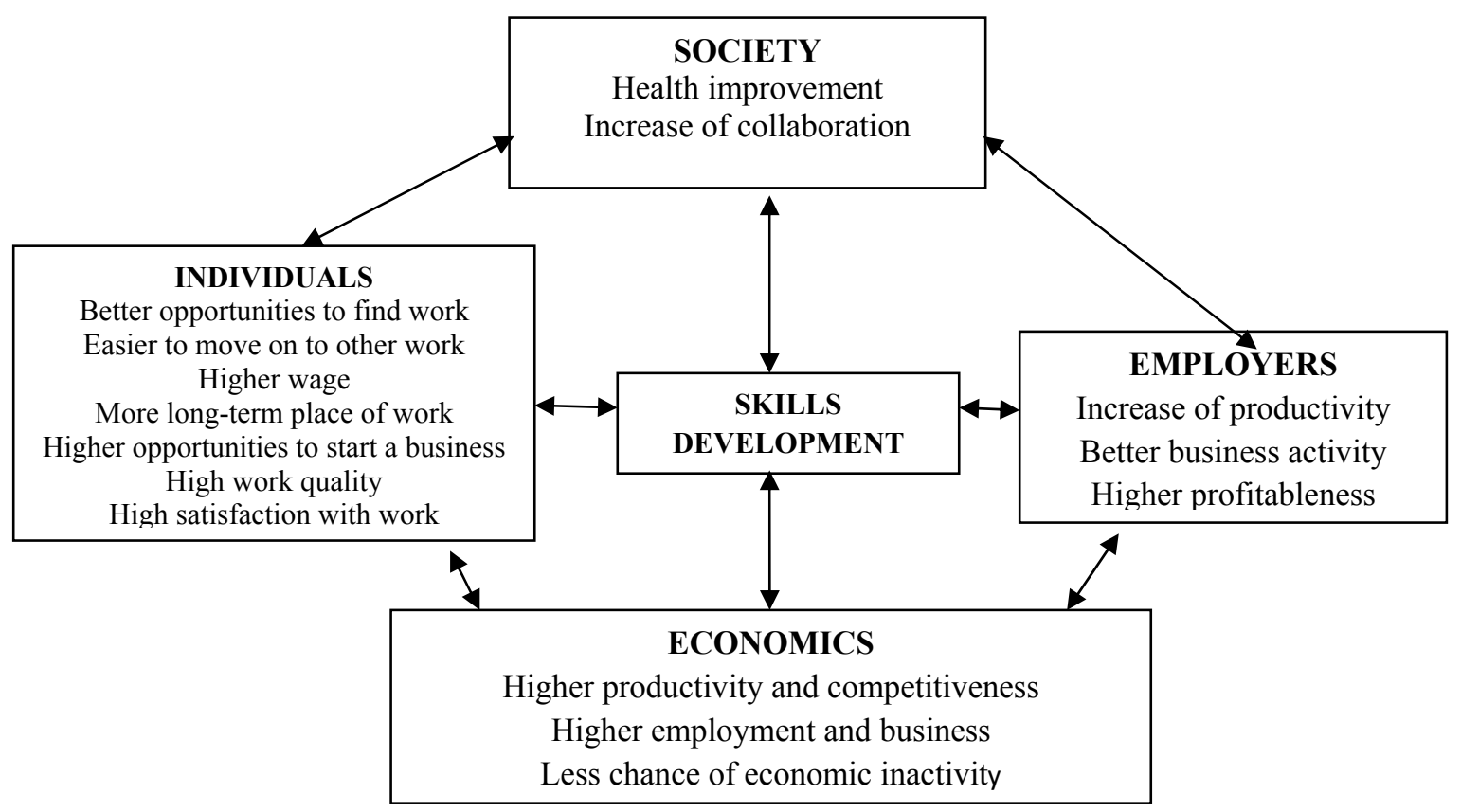

Figure 1 Benefits from skills

The skills are included and form a common system in which the individuals, employers, economics and social contexts are in constant dynamic interaction. A higher skills level will help an individual to find work or an opportunity to get out of unemployment, to be employed and, using a progress, to get a better place of work.

Studying the employees' skills' mismatch to the position it should be examined how the employees could affect economics, in particular, in unstable sectors, which are strongly dependent on changes in international competition. The skills' mismatch should extend to the whole society, but, in particular, to the researchers of this issue, trade and commercial unions. Skilled people often do a simple work, which is a common international phenomenon. In the last Cedefop's review on "Future skills needs in Europe" (Cedefop, 2008) it is observed that from a direct labour force growth - more than 13 million of places of work from 2006 until 2015 in the higher educational level could be around 12,5 millions of vacancies.(CEDEFOP, 2010)

The data on skills mismatch in Europe shows that it is a common phenomenon. A very little understanding of skills mismatch means a low probability of interaction of skills between the types of skills mismatch. Addressing the issues of skills mismatch is particularly important for socially unprotected groups in the labour market, such as migrants, older employees and young people who have completed their studies and have to start their work. The following article analyses situations of two types: 
Overskilling - a situation when a person is not able to fully use their abilities and talents in a current work.

Underskilling - a situation when a person lacks necessary abilities and talents to fulfil the norms of their current work.

\section{The Analysis of Skills Compliance of Employees in the Sector of Latvian Banks}

This study aims to find out the skills matching of the employees working in banking sector to the demands of the sector and to state how the mismatch influences the employees' motivation. The study was conducted in the sector of Latvian commercial banks surveying their employees. The questionnaire was developed using the experience of other countries carrying out similar studies and it requires employees to perform their skills self-esteem. It was based on the study carried out in 2001 in Portugal on skills mismatch in banking sector. In this study an empirical methodology was used which is based on unemployment. The above described methodology has been tested with 600 Portugal (retail) banking employees (Sgobbi, 2009)

In the study 236 employees in Latvia operating commercial banks were surveyed. The survey was anonymous which gave possibility to evaluate more objectively the level of skills matching in the commercial banks. Questionnaires were completed by employees of different levels: customer service specialists (37\%), administrative employees (27\%) and back-office employees (36\%). The survey results showed that the majority of bank employees are aged 25 to 35 $(56 \%)$ what is indicative of good potentialities in skills development.

As the main factors of skill mismatch were determined:

- temporality of skills;

- change of work responsibilities;

- the growing demands in the pace of work;

- insufficient previous training;

- other variant

The survey results show that all these factors are important in the skills mismatch (See Picture 2).

As the main factors the insufficient previous training and the growing demands in the work place were mentioned.

The study has also found out what impression leaves the work skills mismatch on the employees.

In cases if the employee esteems their skills higher than the job responsibilities demand, it was possible to give the following answers:

- You expect to get a job promotion;

- You troubled to lost a qualification;

- You feel undervalued;

- You do not care. 


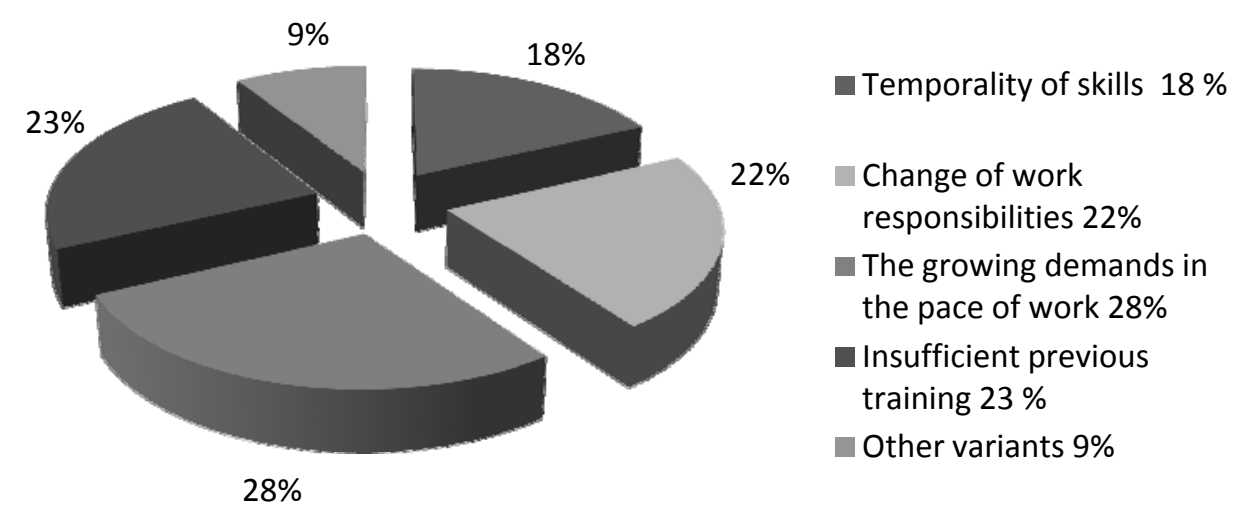

Figure 2 Causes of Skill Mismatch

The survey results show that the majority of respondents in this situation hope to get a job promotion, $38 \%$ are troubled that not using fully their skills they may lost a qualification, but, 24\% feel undervalued (See Picture 3)
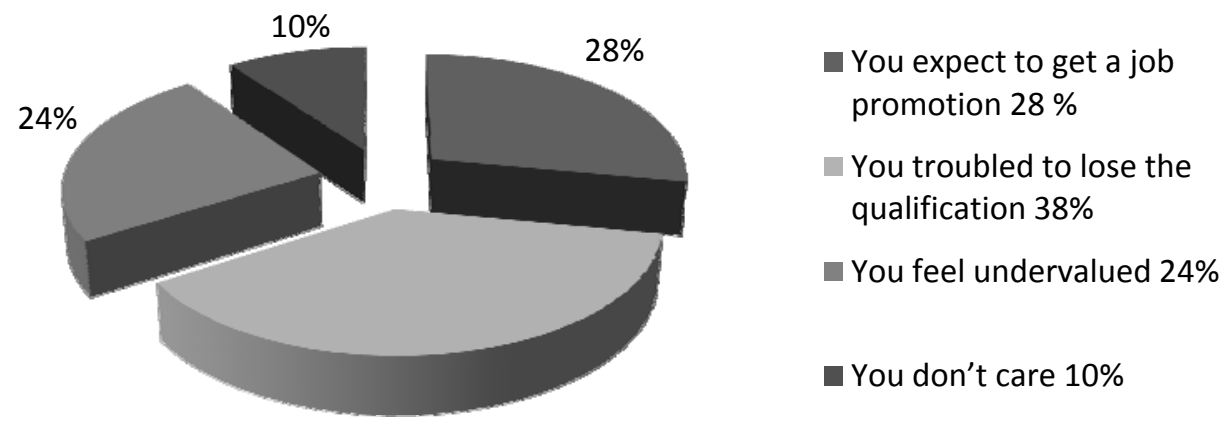

$38 \%$

Figure 3 Arising Effects from High Skill Assessment

In cases if the employee has esteemed their skills as low, then it was possible to choose the following answers:

- You believe that you just do your duties well enough;

- You hope to get the support of employer in improvement of professional skills;

- You feel discomfort and insecurity;

- You do not care.

The answers given show that the majority of respondents hope to get the support of employer, $26 \%$ feel discomfort and insecurity and 10\% of respondents do not care (See Figure 4). 


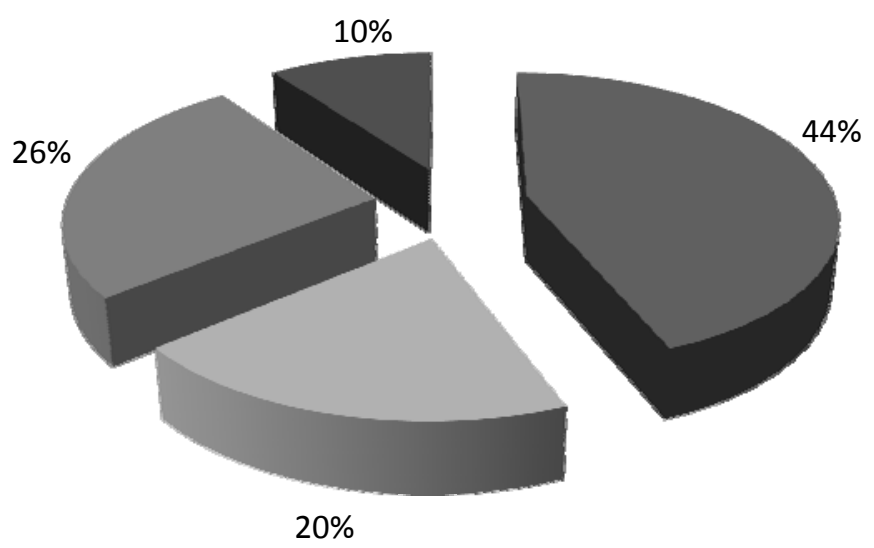

You believe that you just do your duties well enough $44 \%$

You hope to get the support of employer in improvement of professional skills $20 \%$

You feel discomfort and insecurity $26 \%$

- You don't care $10 \%$

Figure 4 Arising Effects from Low Skill Assessment

As important skills of bank employees were nominated - ability to work with clients, persuasion skills, understanding of the process of banking activity.

The survey data shows that the respondents in these positions esteemed their skills as very good or good.

\section{Conclusions}

1. The human work skills and their ability to use them is a special form of capital and its development requires substantial time and material resources to be invested.

2. An unfavourable demographic development and insufficient use of human capital has begun to threaten the perspectives of several countries and their regions.

3. The employees' skills create a common system, in which the individuals, employers and social context interact and affect the national economics.

4. The main reasons for the skills mismatching of Latvian commercial banks employees is the temporality of skills, the change of job duties, the growing demands in the workplace, insufficient previous training.

5. In the Latvian banking sector there is skills mismatching of employees, but it affects about $20 \%$ of respondents. For $1 / 3$ of them it creates tension and insecurity, which influence the work productivity.

\section{References}

1. Becker, G.S. (1975). Human Capital / G. S. Becker. NY.: Columbia University Press.

2. CEDEFOP (2010). The skill matching challenge: analysing skill mismatch and policy implications. Luxembourg: Publications Office of the European Union.

3. Latvia's Sustainable Development Strategy until 2030. (2010). Retrieved from http://www.latvija2030.1v/upload/latvija2030_saeima.pdf 
4. New skills for new jobs: better matching and anticipating labour market needs, European Commission (2010). Retrieved from http://ec.europa.eu/education/news/ news1110_en.htm

5. Schultz, T.W. (1961). Investment in Human Capital. The American Economic Review 1(2), 1-17.

6. Sgobbi, F. (2009). A methodological contribution to the measurement of skill (mis)matc. A draft presented at the Decowe Conference: Ljubljana, Slovenia.

\section{Acknowledgement}

The analysis of employee skills compliance within Latvian Banks has been researched in BA school of Business and Finance in collaboration with the Association of Commercial Banks of Latvia (LKBA).

Mg.sc.edu

Valentina Pavlovska
BA School of Business and Finance

Department of entrepreneurship and IT

Assistant Professor

K.Valdemara Street 161, Riga, LV-1031, Latvia

E-mail: valentina.pavlovska@ba.lv 